\title{
Downregulation of SPARC expression inhibits cell migration and invasion in malignant gliomas
}

\author{
TOSHIMOTO SENO, HIRONOBU HARADA, SHOHEI KOHNO, \\ MIKIO TERAOKA, AKIHIRO INOUE and TAKANORI OHNISHI \\ Department of Neurosurgery, Ehime University School of Medicine, Ehime 791-0295, Japan
}

Received September 25, 2008; Accepted November 24, 2008

DOI: 10.3892/ijo_00000197

\begin{abstract}
The secreted protein acidic and rich in cysteine (SPARC) is a secreted glycoprotein that plays an essential role in promoting the motility of invasive tumor cells. In the present study, we investigated the role of SPARC in the motile and invasive activities of human glioma cells by silencing the SPARC gene. Introduction of SPARC-targeted small interfering RNA (siRNA) into glioma cell lines resulted in downregulation of SPARC expression, and significantly suppressed glioma cell migration in vitro. Furthermore, invasiveness was significantly reduced in the cells transfected with SPARC siRNA compared with those transfected with control siRNA. In an organotypic brain slice model, coculture of glioma spheroids and rat brain slices showed that SPARC siRNA-transfected glioma cells failed to invade the surrounding normal brain tissue. In addition, intracerebral injection of glioma cells transfected with SPARC siRNA in nude mice resulted in the formation of a non-invasive tumor, whereas injection of cells transfected with control siRNA resulted in diffuse invasive tumors. Since SPARC was exclusively expressed in the invasive zone of the tumor margin and the area surrounding tumor necrosis, we investigated the relationship between SPARC expression and hypoxic stress. SPARC expression was upregulated under hypoxic stress of $1 \%$ oxygen concentration in glioma cells. Silencing hypoxia-inducible factor- $1 \alpha$ with siRNA reduced the overexpression of SPARC induced under hypoxic conditions. These results suggest that SPARC plays an essential role in the invasive activity of human glioma cells, under hypoxic conditions. Downregulation of SPARC may be a novel antiinvasion therapeutic strategy for malignant gliomas.
\end{abstract}

Correspondence to: Dr Toshimoto Seno, Department of Neurosurgery, Ehime University School of Medicine, Shitsukawa, Toon, Ehime 791-0295, Japan

E-mail: tseno@m.ehime-u.ac.jp

Key words: SPARC, invasion, siRNA, glioma

\section{Introduction}

Glioblastomas are the most common primary malignant brain tumors, which are most resistant to treatment, and for the majority of patients, the probability of survival remains very low despite aggressive treatment including surgical resection, radiation therapy, and chemotherapy. A crucial reason for poor prognosis is the highly invasive nature of the tumor, which makes radical surgical resection very difficult. To establish an effective strategy in the treatment of malignant gliomas, molecular mechanisms of tumor invasion must be understood and investigated.

Increased cell motility with local degradation of the extracellular matrix (ECM) is essential for tumor cell invasion. The structural and regulatory proteins of the ECM cooperatively function to regulate a variety of cellular processes, including cell migration and adhesion. Therefore, a better understanding of the biological interaction between ECM components and glioma cells is critical to elucidate the mechanism of glioma invasion.

The secreted protein acidic and rich in cysteine (SPARC), also known as osteonectin, is an extracellular matrixassociated glycoprotein, first identified as a major noncollagenous constituent of bovine bone (1). This protein does not function as a cell adhesion molecule in most cells, but has an anti-adhesive function that leads to cell rounding and partial detachment from the ECM (2). It is possible that SPARC interacts with a protein on the cell surface to induce morpho-logical changes of the cells and release them from the ECM $(3,4)$. It has been suggested that such a de-adhesive function will promote cell movement by reducing strong cell adhesions to moderate levels (5).

SPARC is highly expressed in gliomas, and an immunohistochemical study demonstrated that the molecule is overexpressed in all astrocytic gliomas, especially showing higher levels at the site of tumor invasion and in the area of neovascularization on tumor surface (6). In gliomas, it has been reported that overexpression of SPARC increases the invasion both in vitro and in vivo $(7,8)$, and increased levels of SPARC expression are related to poorer survival rates (10). Therefore, targeting SPARC expression may present a therapeutically effective way for anti-invasion of malignant gliomas.

SPARC expression is known to be associated not only with tissue remodeling processes such as wound healing and 
angiogenesis but also with cellular responses to various kinds of stress $(2,3)$. Hypoxia-inducible factor- $1 \alpha$ HIF- $1 \alpha$ is a critical protein that is activated under hypoxic stress, often detected in solid tumors under hypoxic conditions, and is related to cell proliferation, cell survival, and angiogenesis. We previously reported that overexpression of $H I F-1 \alpha$ induced by hypoxic stress is an essential event in the activation of glioma cell motility through alteration of invasion-related molecules (11).

In this study, we investigated whether downregulation of SPARC alters the motility and invasive activity of human glioma cells both in vitro and in vivo. We also analyzed whether hypoxic stress can change the expression of SPARC particularly in relation to the overexpression of $H I F-1 \alpha$.

\section{Materials and methods}

Cell cultures, treatment with small interfering RNA (siRNA), and hypoxic conditions. Human malignant glioma cell lines U251MG and U373MG were generously provided by Dr N. Arita (Hyogo College of Medicine, Hyogo, Japan). Both glioma cell lines were maintained in Dulbecco's modified Eagle's medium (DMEM) containing 10\% heat-inactivated fetal bovine serum (FBS) and antibiotics (penicillin G, $100 \mathrm{U} / \mathrm{ml}$ and streptomycin, $100 \mu \mathrm{g} / \mathrm{ml}$ ) and incubated at $37^{\circ} \mathrm{C}$ under the standard conditions of $100 \%$ humidity, $95 \%$ air, and $5 \% \mathrm{CO}_{2}$.

SPARC siRNA was designed by searching the coding sequence of SPARC (GenBank accession No. NM_003118). The forward and reverse RNA strands (CGA UGU UGU CAA GGA UGG U $d t d t$ ) and (GCU ACA ACA GUU CCU ACC A $d t d t$ ) were synthesized and annealed (Dharmacon Research, Inc.). As a control for SPARC siRNA, we used a corresponding random siRNA sequence (UGA GAC CGA AGU UUU GGG U $d t d t$ ). HIF- $1 \alpha$ siRNA was designed by searching the coding sequence of HIF-1 $\alpha$ (GenBank accession No. NM_001530). The forward and reverse RNA strands (CUA ACU GGA CAC AGU GUG U $d t d t$ ) and (ACA CAC UGU GUC CAG UUA G $d t d t$ ) were synthesized and annealed (Dharmacon Research, Inc.). As a control for HIF- $1 \alpha$ siRNA, we used a corresponding random siRNA sequence (AUU GUA UGC GAU CGC AGA C $d t d t$ ). These sequences were checked for non-homology to any human gene by BLAST. For transfection, $2 \mu 1$ siLentFect lipid reagent (Bio-Rad Laboratories, Hercules, CA) was mixed with $98 \mu 1$ of Opti-MEM (Invitrogen, San Diego, USA), and SPARC siRNA was diluted with Opti-MEM to obtain $200 \mu 1$ of $60 \mathrm{nM}$ solution. These two solutions were combined, gently mixed, and incubated at room temperature for $15 \mathrm{~min}$ to form the transfection mixture. All glioma cell lines $\left(1 \times 10^{5}\right.$ in $2 \mathrm{ml}$ of a medium containing serum) were seeded in 6-well plates and incubated for $24 \mathrm{~h}$ before the transfection. Then, DMEM was removed and replaced with $1 \mathrm{ml}$ of the same fresh medium. The transfection mixture was added to all cultures, making a final siRNA concentration of $10 \mathrm{nM}$, and the cells were incubated at $37^{\circ} \mathrm{C}$ for $6 \mathrm{~h}$. The mixture was replaced with a fresh medium containing serum, and glioma cells were assayed from $16 \mathrm{~h}$ thereafter.

For hypoxic treatment, the cells were incubated in an atmosphere of $1 \% \mathrm{O}_{2}, 5 \% \mathrm{CO}_{2}$, and $94 \% \mathrm{~N}_{2}$ under intermittent flushing with nitrogen, then sealed and incubated at $37^{\circ} \mathrm{C}$ for $48 \mathrm{~h}$.

Western blot analysis. The culture dishes were immediately placed on ice and washed twice with ice-cold phosphatebuffered saline (PBS) and harvested in lysis buffer. Protein concentrations were determined with a BCA protein assay kit (Piece Biotechnology, Inc. Rockford, IL). Protein (10 $\mu \mathrm{g})$ from each sample was separated by $10 \%$ sodium dodecyl sulfate-Tris glycine gel electrophoresis and transferred onto a polyvinylidene difluoride membrane (Bio-Rad Laboratories). The membranes were blocked with $1 \%$ dry milk and $0.1 \%$ Tween-20 in Tris-buffered saline and incubated with primary antibodies, mouse anti-human SPARC monoclonal antibody (Hematologic Technologies Inc.), mouse anti-human HIF-1 $\alpha$ monoclonal antibody (Transduction Laboratories), and mouse anti- $\beta$-actin monoclonal antibody (Sigma-Aldrich Fine Chemical, St. Louis, MO), followed by incubation with horseradish peroxidase-conjugated sheep anti-mouse IgG antibody (Amersham, Piscataway, NJ). The membranes were developed according to the Amersham enhanced chemiluminescence protocol.

Cell viability assay. The MTT assay was performed according to the method of Mosmann et al (12). In brief, $3 \times 10^{3}$ cells (U251MG and U373MG) were seeded in each well of 96-well flat-bottom plates. Twenty-four hours after the incubation, SPARC siRNA and control siRNA were transfected as described. At $72 \mathrm{~h}$ following incubation, $10 \mu 1 \mathrm{MTT}$ $(5 \mathrm{mg} / \mathrm{ml})$ was added, and the plates were incubated for additional $4 \mathrm{~h}$. The culture medium was removed, formazan crystals were dissolved in $100 \mu 1$ isopropanol with $0.04 \mathrm{~N}$ $\mathrm{HCl}$, and absorbance was read on a microplate reader (SPECTRAmax, Molecular Device Corp.) at $540 \mathrm{~nm}$ and a reference wavelength of $620 \mathrm{~nm}$.

In vitro migration assay. Migratory responses of glioma cells to their own conditioned medium were assessed using the modified Boyden chamber method with 48-well microchemotaxis chambers (Nucleopore, Pleasanton, CA) as previously described $(13,14)$. In brief, glioma cells transfected with SPARC siRNA or control siRNA were harvested and resuspended in DMEM containing $0.1 \%$ BSA at a density of $8 \times 10^{5}$ cells $/ \mathrm{ml}$. Cell suspensions $(30 \mu \mathrm{l})$ were placed in the upper well of the chamber, and a serum-free conditioned medium was placed in the lower well as a chemoattractant. The filter was a polyvinylpyrolidone-free polycarbonate membrane with $8-\mu \mathrm{m}$ pores (Millipore, Bedford, MA). The chamber was incubated for $6 \mathrm{~h}$ at $37^{\circ} \mathrm{C}$ under the standard conditions as described above, and the cells that migrated to the lower surface of the filter were fixed and stained with Diff-Quik (Scientific Products, Harleco, Gibbstown, NJ). Cells were counted in three independent fields $\left(0.25 \mathrm{~mm}^{2} /\right.$ well $)$.

In vitro invasion assay. The invasive activity of glioma cells was assayed in vitro using Falcon cell culture inserts (BectonDickinson Biosciences, USA) and a reconstituted basement membrane, Matrigel (Becton-Dickinson Biosciences), as previously described (15-18). In brief, glioma cells treated with SPARC siRNA or control siRNA in DMEM containing 
$0.1 \%$ BSA were seeded onto the upper sides of insert filters coated with Matrigel (60 $\mu \mathrm{g}$ /insert) at a density of $1 \times 10^{5}$ cells/insert. The lower compartment of the Falcon 24-well plates contained $500 \mu 1$ of the conditioned medium as a chemoattractant. After 2 days at $37^{\circ} \mathrm{C}$ under standard conditions, the lower surfaces of the culture inserts were fixed and stained with Diff-Quik. In vitro cell invasive activities were quantified as described for the migration assays.

Invasion assay in brain slice model. All animal experiments were conducted in accordance with the guidelines for animal experimentation of the Ehime University Committee for Ethics of Animal Experimentation. To assess the effect of SPARC suppression on cell motility under more physiological conditions, we used rat brain slice culture, which mimics in vivo central nervous system conditions. A slice culture of the rat whole cerebrum was produced by modifying an organotypic culture method described previously (19-21). Brain slices were prepared from 2-day-old neonatal female Wistar rats (SLC Inc., Japan). After brief anesthesia with diethyl ether, the rats were decapitated using scissors and the heads were immersed in $10 \%$ povidone-iodine solution. The whole brains were quickly removed and placed in Hanks' balanced salt solution (HBSS; Life Technologies, Inc., Rockville, MD). The brains were mounted on the stage of a microslicer (Dosaka EM Co., Ltd., Kyoto, Japan) and cut into 500- $\mu \mathrm{m}$ coronal slices, which were transferred onto $30-\mu \mathrm{m}$ Millicell-CM inserts with $0.4-\mu \mathrm{m}$ pores (Millipore) in 6-well culture plates. The wells contained $1 \mathrm{ml}$ of $50 \%$ Eagle's minimal essential medium with HEPES, 25\% HBSS, $25 \%$ heat-inactivated horse serum (Life Technologies Inc.), $6.5 \mathrm{mg} / \mathrm{ml}$ glucose, 100 units $/ \mathrm{ml}$ penicillin, $100 \mu \mathrm{g} / \mathrm{ml} \mathrm{strep-}$ tomycin, and $2.5 \mu \mathrm{g} / \mathrm{ml}$ amphotericin B (Fungizone). Brain slices were incubated at $37^{\circ} \mathrm{C}$ in a humidified atmosphere of $95 \%$ air and $5 \% \mathrm{CO}_{2}$. The culture medium was replaced with a fresh medium twice each week.

U251MG and U373MG cells transfected with SPARC siRNA or control siRNA were fluorescently labeled with PKH26 (rhodamine) using a kit (Zynaxis Cell Science, Inc., Malvern, PA) as described previously (19). In brief, $1 \times 10^{7}$ harvested glioma cells in serum-free DMEM were resuspended in $1 \mathrm{ml}$ of diluent $\mathrm{C}$, and then PKH26 dye in $1 \mathrm{ml}$ of diluent $\mathrm{C}\left(2 \times 10^{-6} \mathrm{M}\right)$ was added. After incubation of the cells at room temperature for $5 \mathrm{~min}$, the labeling reaction was stopped by adding $2 \mathrm{ml}$ of FBS. After adding $4 \mathrm{ml}$ of DMEM containing 10\% FBS, free PKH26 dye was removed by thoroughly washing the cells. The labeled glioma cells $\left(5 \times 10^{5}\right)$ seeded into non-treated $60-\mathrm{mm}$ culture dishes were continuously agitated at a speed of $30 \mathrm{rpm}$ on a reciprocating shaker (Taitec, Saitama, Japan) at $37^{\circ} \mathrm{C}$ under the standard conditions to form 300-400 $\mu \mathrm{m}$ spheroids. The rhodaminelabeled glioma cell spheroids were pipetted, placed on a brain slice as close to the corpus callosum as possible, and cocultured at $37^{\circ} \mathrm{C}$ under the standard conditions for 3 days. Cell invasion was observed by fluorescence microscopy on day 3 .

U251MG cells transplantation model. Nude mice (6-8 weeks old) anesthetized with $0.8 \mathrm{mg} / \mathrm{kg}$ of pentobarbital sodium (Schering-Plough) were held in a stereotactic frame. A midline skin incision was made in the head, and a burr hole was drilled in the skull $1 \mathrm{~mm}$ anterior to the coronal suture and $1.5 \mathrm{~mm}$ lateral to the midline to expose the dura. Rhodaminelabeled U251MG cells $\left(1 \times 10^{5}\right)$ treated with SPARC siRNA or control siRNA in $3 \mu \mathrm{l}$ of PBS were injected to a depth of $3 \mathrm{~mm}$ from the dura mater using a Hamilton syringe (Reno, NV) connected to the stereotactic frame. The needle was retrained for $3 \mathrm{~min}$ and slowly withdrawn over a 2-min period.

Three days after tumor transplantation, the rats were decapitated. The whole brain was removed and fixed in $4 \%$ paraformaldehyde in PBS containing $2 \mathrm{mmol} / 1 \mathrm{MgCl}_{2}$. The dissected brains were immersed in $15 \%$ sucrose in PBS at $4^{\circ} \mathrm{C}$ overnight, rapidly frozen in dry ice powder, and sliced at the caudate-putamen level into $10-\mu \mathrm{mm}$ thick coronal sections using a cryostat. The invasive activity of rhodamine-labeled U251MG cells in coronal sections was observed under a fluorescence microscope.

Statistical analysis. The results were representative of experiments repeated at least three times and the values were expressed as means \pm standard deviation. Statistical comparisons between groups were performed using Student's t-test (Stat View, SAS Institute Inc., NC). p-values $<0.05$ were considered statistically significant.

\section{Results}

Effects of SPARC siRNA in glioma cells. SPARC protein levels in the cell lysate and conditioned medium after transfection with SPARC siRNA or control siRNA were assayed by Western blot analysis. Transfection with SPARC siRNA markedly inhibited the expression of SPARC protein compared with that of control siRNA and mock in both U251MG and U373MG cells (Fig. 1A). To examine the duration of inhibition of SPARC synthesis by SPARC siRNA, glioma cells were transfected with SPARC siRNA and cultured for 48, $96 \mathrm{~h}$, and 7 days. A clear band indicating SPARC was not seen until $96 \mathrm{~h}$ of incubation in both glioma cells, whereas emergence of the protein was apparent on day 7 in U373MG cells (Fig. 1B).

Moreover, we examined the influence of siRNA on cell viability. Cell viability after treatment with SPARC siRNA or control siRNA was assessed by the MTT assay. At $72 \mathrm{~h}$ after transfection, there was no difference in cell viability among SPARC siRNA treatment, control siRNA treatment, and no treatment (Fig. 2). Therefore, we performed subsequent studies not more than $72 \mathrm{~h}$ after transfection with siRNA.

Downregulation of SPARC expression inhibits glioma cell migration and invasion in vitro. To examine effects of SPARC on the migratory ability of glioma cells, we performed a migration assay using a modified Boyden chamber method. Migration of glioma cells transfected with SPARC siRNA was significantly reduced compared with the mock and control siRNA-transfected cells in both U251MG and U373MG cells (Fig. 3).

We investigated the influence of SPARC protein on the glioma cell invasive activity using an in vitro invasion assay. The microphotographs in Fig. 4A show U251MG and U373MG cells invading through Matrigel after $48 \mathrm{~h}$ of incubation with SPARC siRNA, with control siRNA, or 
A

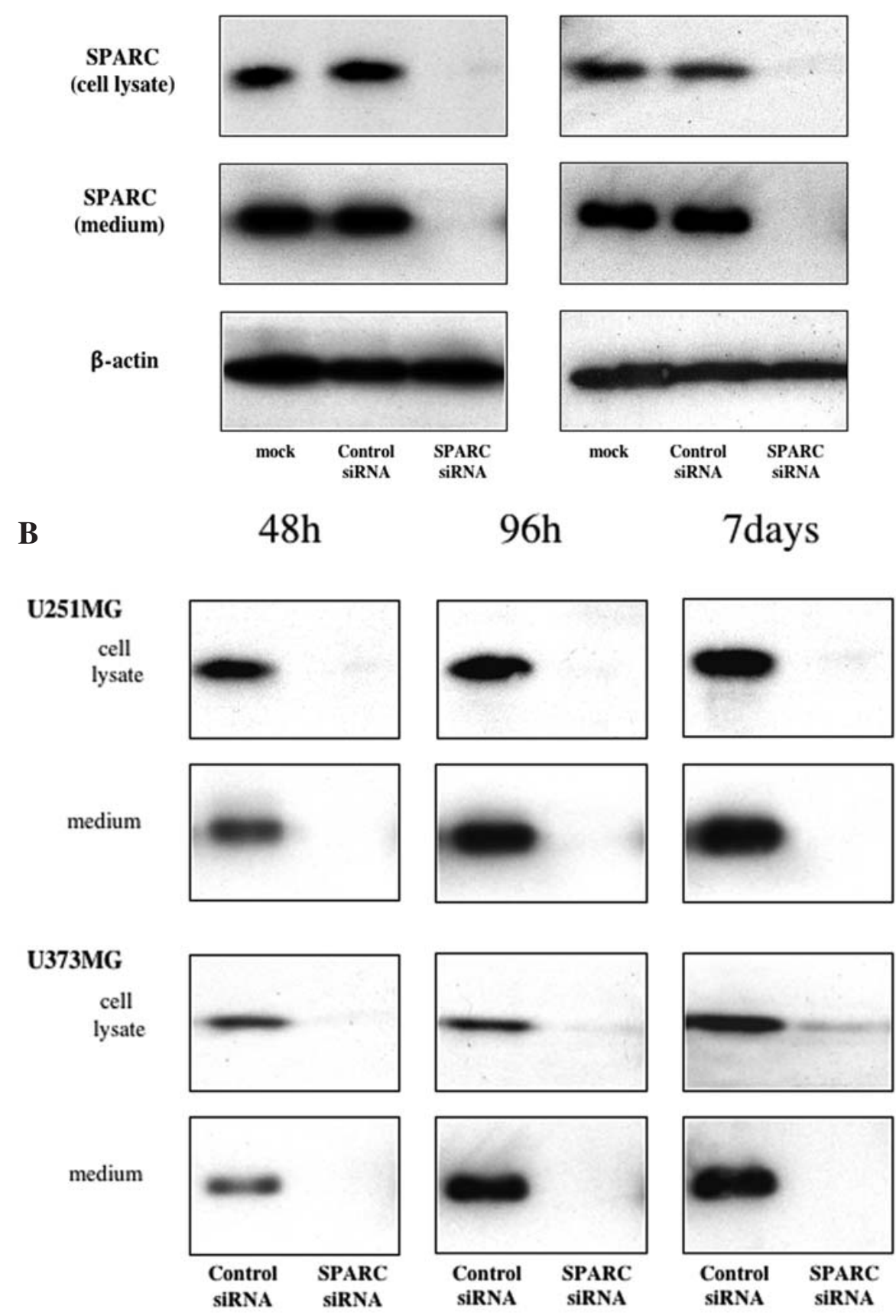

Figure 1. Effects of SPARC siRNA on SPARC protein expression were examined by Western blot analysis. (A) SPARC protein expression in the cell lysate and medium in non-treated cells (mock), cells treated with control siRNA, and those treated with SPARC siRNA is shown. Transfection with SPARC siRNA repressed SPARC protein synthesis in both the cell lysate and medium in U251MG and U373MG cells. (B) Effect of SPARC siRNA on SPARC expression at 48, $96 \mathrm{~h}$, and 7 days after transfection with control siRNA and SPARC siRNA. A band of SRARC was not clearly seen until $96 \mathrm{~h}$ after transfection, whereas SRARC expression was observed in the cell lysate of U373MG cells after 7 days.

without siRNA (mock). The invasive potential of glioma cells transfected with SPARC siRNA was significantly reduced compared with cells treated with control siRNA (Fig. 4B).

Suppression of SPARC expression inhibits glioma cell invasion in a brain slice model. To evaluate the effects of SPARC siRNA on cell motility under more physiological conditions, we investigated the extent of migration of glioma cells treated with SPARC siRNA and control siRNA in an organotypic rat brain slice. The brain slice model enabled us to evaluate the invasion of glioma cells into the surrounding brain tissue in conditions analogous to those of normal brain in situ. We implanted a rhodamine-labeled spheroid of each glioma cell onto the corpus callosum of the cerebral hemisphere (22). Glioma cells transfected with control siRNA or without siRNA actively migrated and infiltrated into the brain tissue around tumor spheroids, whereas glioma cells treated with SPARC siRNA showed decreased migration into the surrounding normal brain tissue (Fig. 5). 
U251MG

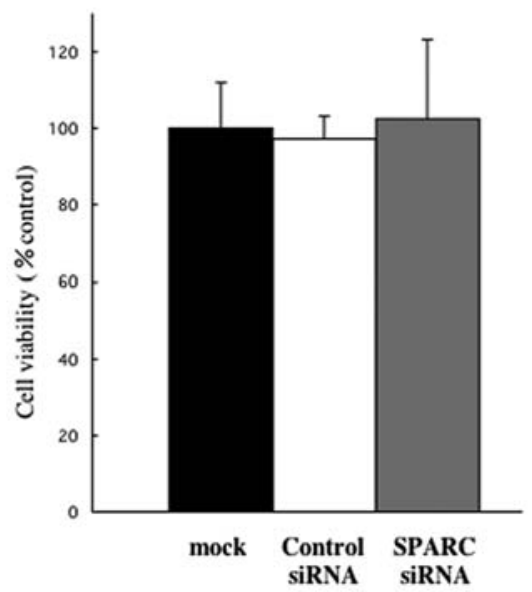

U373MG

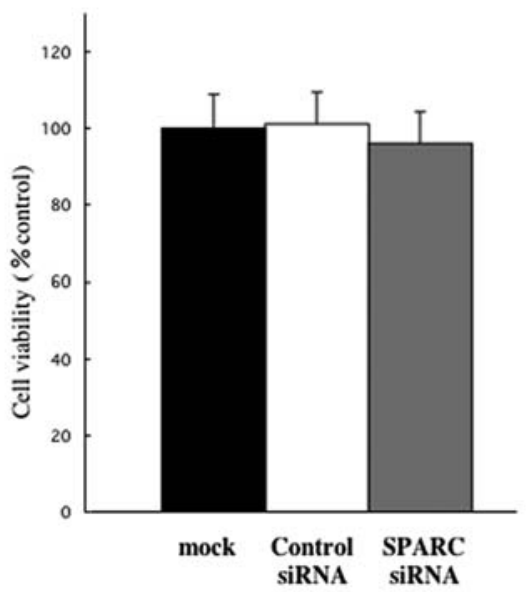

Figure 2. Cell viability after introduction of siRNA was assessed by the MTT assay. The glioma cells were seeded at $3 \times 10^{3}$ cells/well in 96 -well flat-bottom plates. The cells were incubated for $72 \mathrm{~h}$ after siRNA transfection. Then, absorbance was read on a microplate reader at dual wavelengths of 540 and 620 nm. Cell viability did not differ between treatments with SPARC siRNA (gray) and control siRNA (white). Values represent means \pm SD of four experiments.

\section{U251MG}

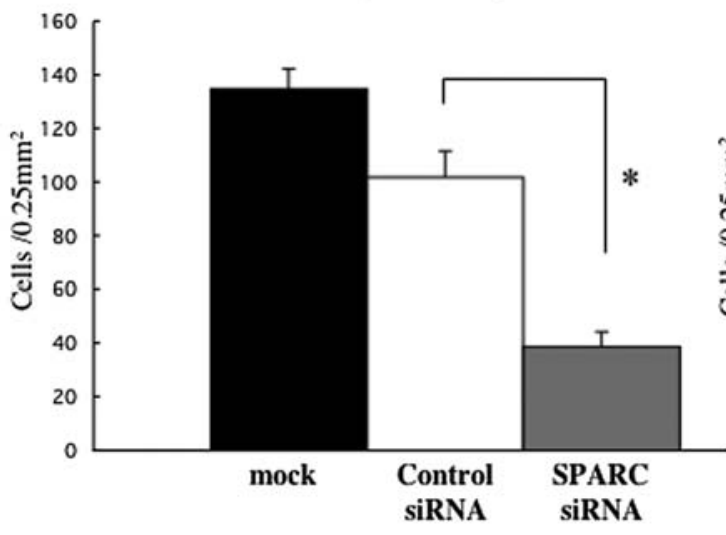

U373MG

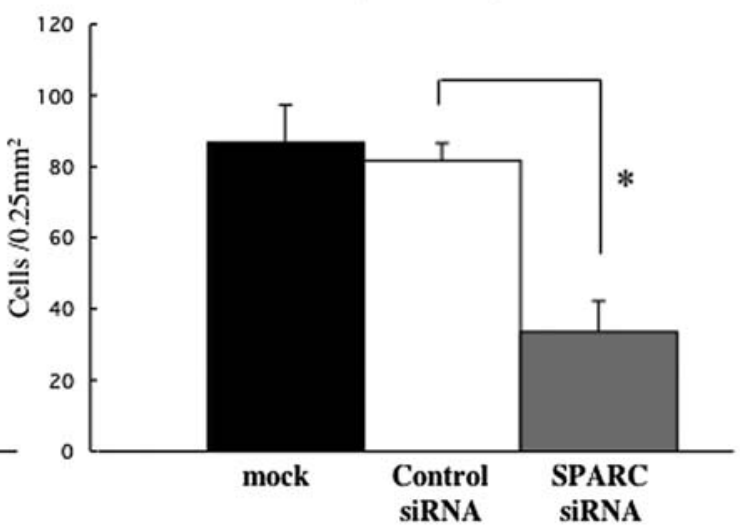

$* \mathrm{P}<0.005$

Figure 3. Effects of SPARC siRNA on the migration activity of glioma cells. Migration activity was evaluated by a modified Boyden chamber assay method. Non-treated cells (mock), cells treated with control siRNA, and those treated with SPARC siRNA were placed in the upper well. The conditioned medium of each group of cells served as a chemoattractant in the lower well. Cells that migrated to the lower surface of the membrane, which had 8- $\mu \mathrm{m}$ pores, were stained with Diff-Quik and counted. Migration of glioma cells transfected with SPARC siRNA (gray) was significantly reduced compared with that of non-treated cells (black) and control siRNA (white). Values represent means \pm SD of three experiments. " $\mathrm{p}<0.005$.

To assess the effect of inhibition of SPARC in vivo, we transplanted rhodamine-labeled U251MG cells that had been transfected with SPARC siRNA or control siRNA into the brains of nude mice. Three days later, whole brains were removed and serially cut into coronal slices. Fluorescence microscopy revealed that cells treated with control siRNA invaded diffusely into the brain tissue around the tumor. In contrast, glioma cells treated with SPARC siRNA formed non-invasive solid tumors (Fig. 6).

HIF-1a induced by hypoxic stress regulates SPARC expression. We examined SPARC expression under hypoxic stress. In this study, a concentration of $1 \% \mathrm{O}_{2}$ was used to induce hypoxia. Low and moderate levels of HIF-1a and SPARC expression, respectively, were detected under normoxia. After $48 \mathrm{~h}$ of hypoxic treatment, both HIF-1 $\alpha$ and SPARC proteins were markedly overexpressed compared with those under normoxic conditions (Fig. 7).

Next, we examined the effect of HIF- $1 \alpha$ siRNA on SPARC protein expression under hypoxic conditions. Transfection with HIF-1 $\alpha$ siRNA markedly suppressed the overexpression of HIF- $1 \alpha$ after hypoxic treatment for $48 \mathrm{~h}$ compared with that of control siRNA and mock in both glioma cells. Furthermore, the expression of SPARC was reduced in the cells transfected with HIF-1 $\alpha$ siRNA compared with those transfected with control siRNA (Fig. 8). These results indicate that SPARC expression was upregulated under hypoxic stress, and downregulation of HIF- $1 \alpha$ reduced SPARC expression, especially under hypoxic conditions in glioma cells. 
A

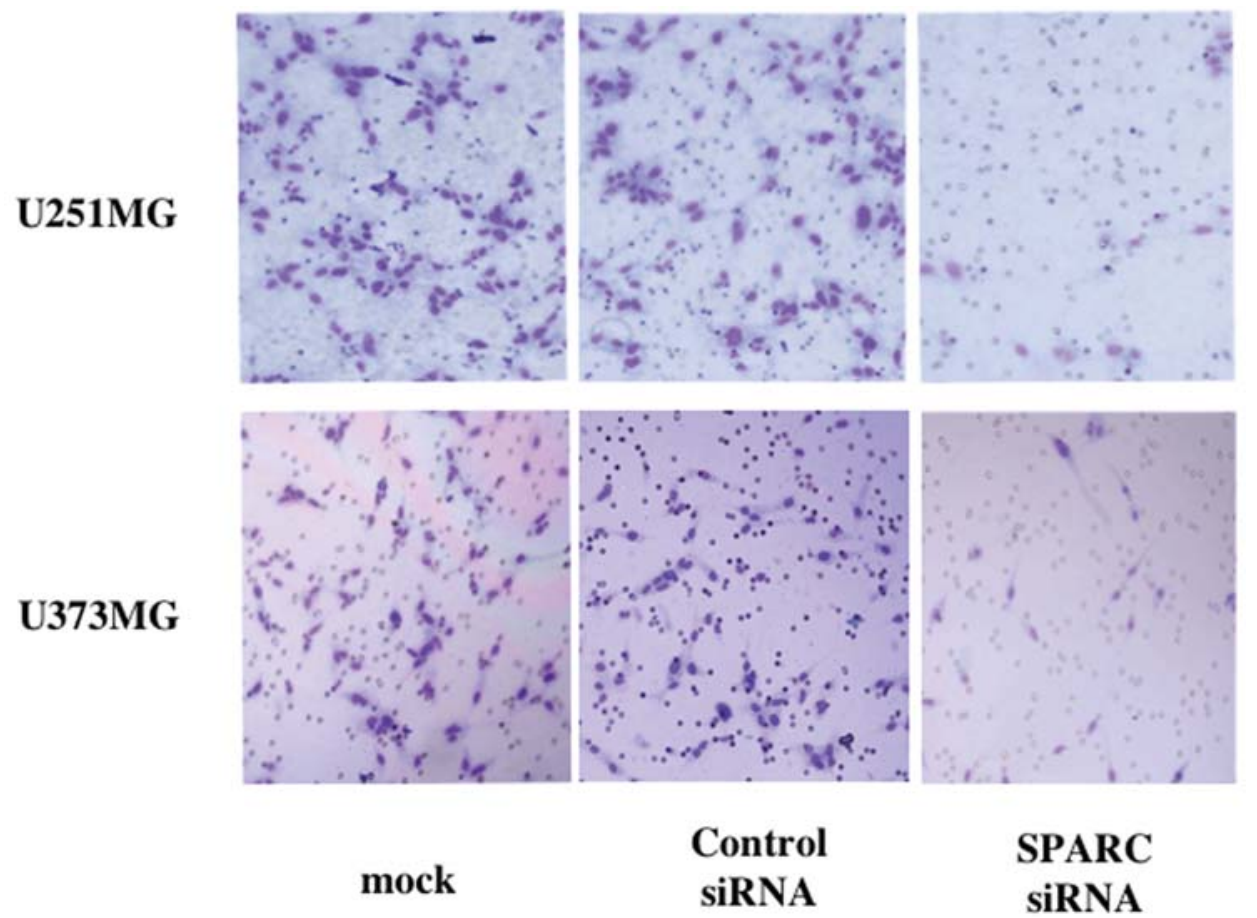

B

U251MG

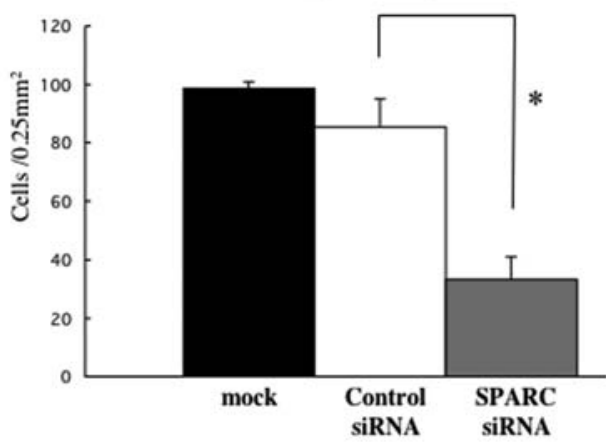

\section{siRNA}

SIRNA
U373MG

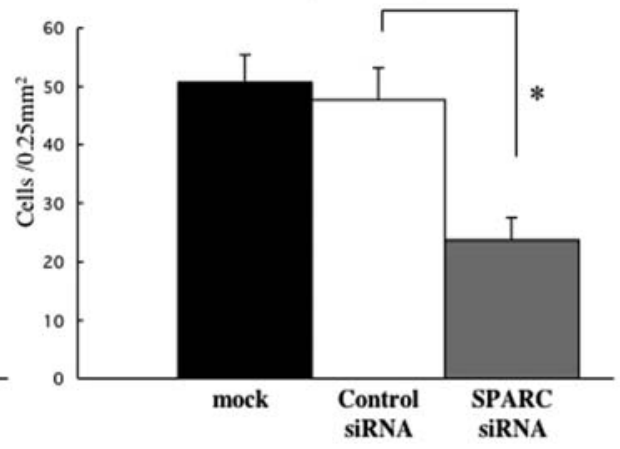

* $\mathrm{P}<0.005$

Figure 4. Effects of SPARC siRNA on glioma cell invasion in vitro. (A) Microphotographs show that U251MG (upper) and U373MG (lower) cells invaded Matrigel to the lower side of an insert filter with $8-\mu \mathrm{m}$ pores $48 \mathrm{~h}$ after incubation. The conditioned medium from glioma cells transfected with siRNA served as a chemoattractant in the lower wells of Falcon 24-well plates. Filters were stained with Diff-Quick. Original magnification was x200. Left, non-treated (mock); middle, control siRNA; right, SPARC siRNA. (B) Number of invading cells was counted after $48 \mathrm{~h}$ of incubation. The invasiveness of glioma cells transfected with SPARC siRNA (gray) was significantly suppressed compared with the cells treated with control siRNA (white) and non-treated cells (black). Values represent means \pm SD of three experiments. ${ }^{*} \mathrm{p}<0.005$.

\section{Discussion}

It is known that SPARC is overexpressed in several malignant tumors. In gliomas, regardless of grade, SPARC was highly expressed in the peripheral regions of tumors as well as adjacent to the normal brain tissue (6). Our immunohistochemical studies revealed that SPARC was overexpressed in the surgical specimens of malignant gliomas, especially in the area of necrosis and in tumor cells adjacent to the normal brain tissue at the tumor-brain interface (data not shown). Therefore, we hypothesized that SPARC may be a key molecule in glioma invasion, and that targeting SPARC may present a novel therapeutic strategy for anti-invasion of malignant gliomas.

In the present study, high levels of intracellular as well as extracellular expression of SPARC have been confirmed in U251MG and U373MG glioma cells. It is generally considered that SPARC exerts its effect extracellularly either through an antagonistic action on integrin receptor signaling or through binding to unidentified homogeneous receptors (23). A recent report provides the evidence that the endocytosis of extracellular SPARC is followed by nuclear translocation. Therefore, it is also likely that SPARC exerts its effect intracellularly (24).

We investigated whether the suppression of SPARC expression by introducing SPARC siRNA can inhibit the migration and invasion of human glioma cells. We used the siRNA technique to inhibit SPARC expression, because siRNA can almost completely suppress expression of RNA and protein for relatively long durations. The SPARC siRNA designed in this study completely suppressed both intracellular and extracellular levels of SPARC expression for at 

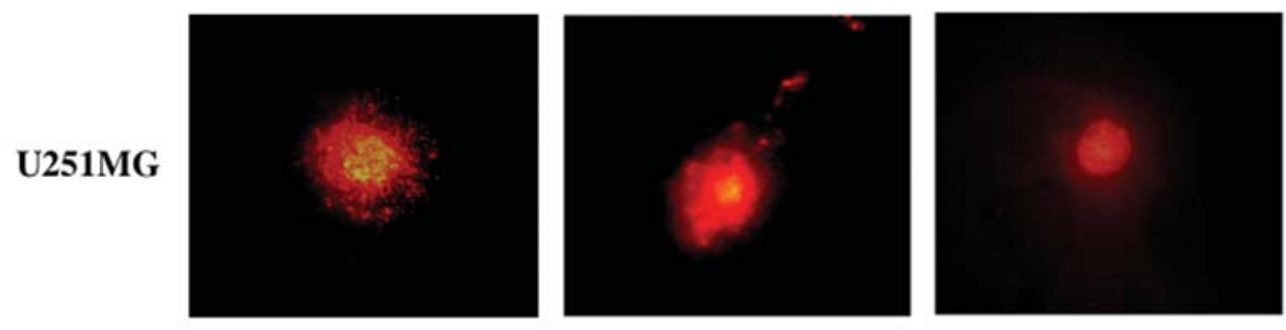

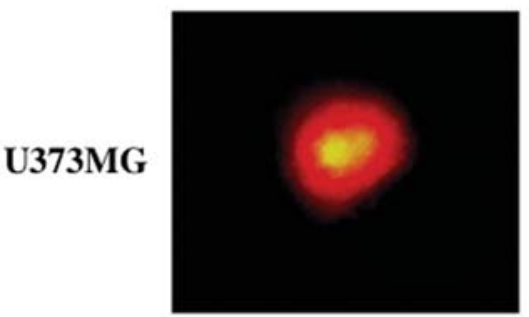

mock

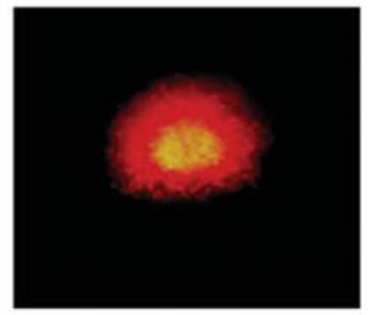

Control

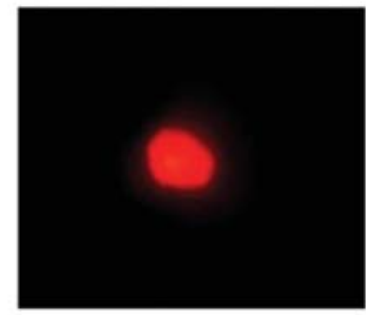

SPARC SIRNA

Figure 5. Invasive behavior of glioma cells transfected with SPARC siRNA on rat brain slices. Rhodamine-labeled glioma cell spheroids were co-cultured with a rat brain slice. Fluorescence microphotographs show U251MG (upper) and U373MG (lower) glioma cell invasion around the original glioma spheroids at day 3. Left, non-treated (mock); middle, control siRNA; and right, SPARC siRNA. Original magnification, x40.
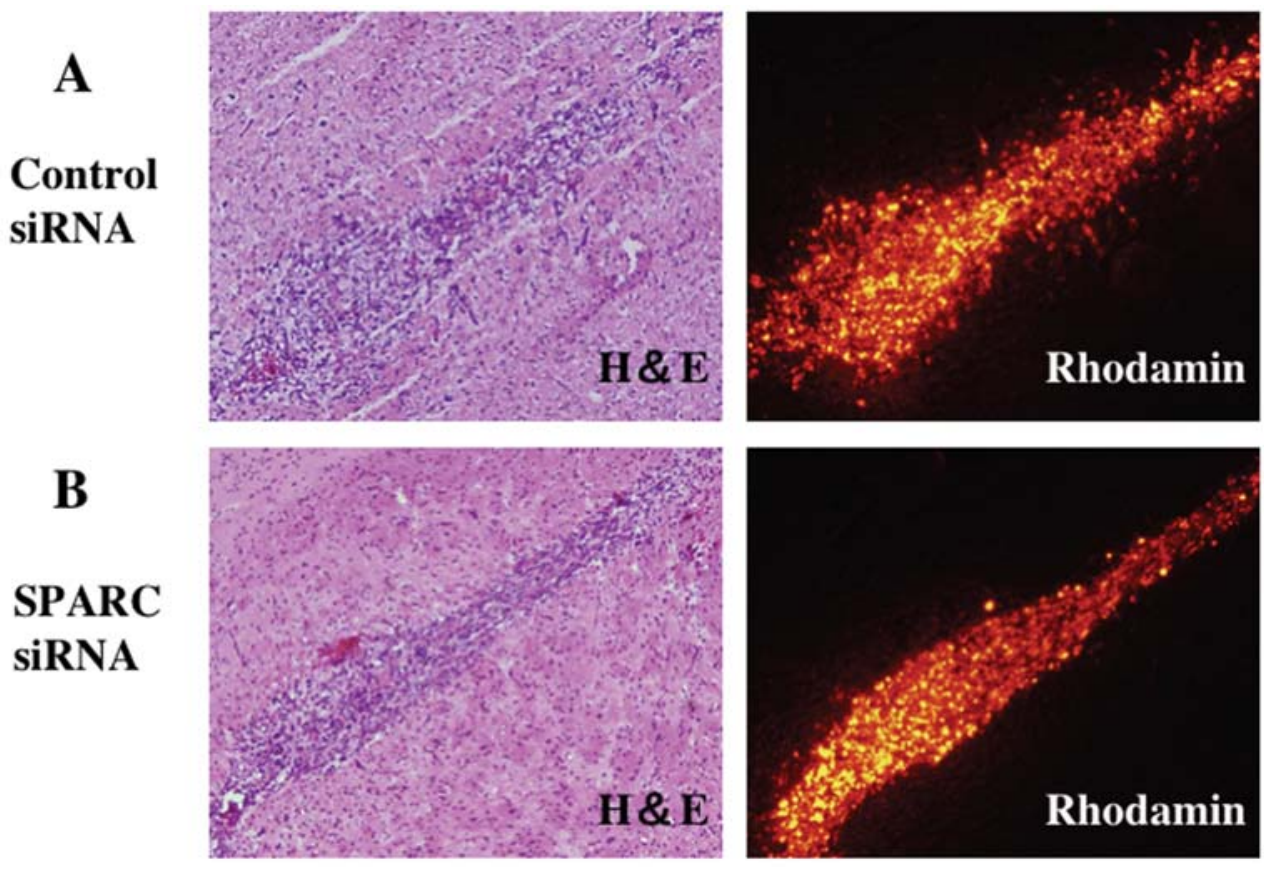

Figure 6. Effects of SPARC on the invasive activity of glioma cells transplanted into nude mice brains. Rhodamine-labeled U251MG cells treated with SPARC siRNA or control siRNA were stereotactically injected into the brains of nude mice. Three days after glioma cell transplantation, cell invasion was observed. (A) Microphotographs showing invasive tumor after intracerebral transplantation of control siRNA-treated glioma cells. Left, H\&E. Right, fluorescent microphotograph. (B) Microphotographs show relatively solid non-invasive tumor mass after intracerebral transplantation of glioma cells treated with SPARC siRNA. Original magnification $\mathrm{x} 100$.

least 4 days, thus demonstrating that the current silencing strategy of the targeted gene is highly effective for evaluating not only extracellular but also intracellular events.

Previous reports indicate that SPARC may modulate glioma proliferation by regulating the growth of glioma cells. SPARC expression delayed cell growth during the log phase but did not inhibit the overall growth (7). In this study, no increasing effect of SPARC siRNA on cell proliferative potential was observed when evaluated with the MTT assay.

In the current study, we demonstrated that the silencing of SPARC expression by SPARC-specific RNA interference can lead to drastic decreases in cell migration and invasion in vitro. Tumor cell invasion is a complex cellular phenomenon that involves cell-cell and cell-extracellular matrix 
U251MG

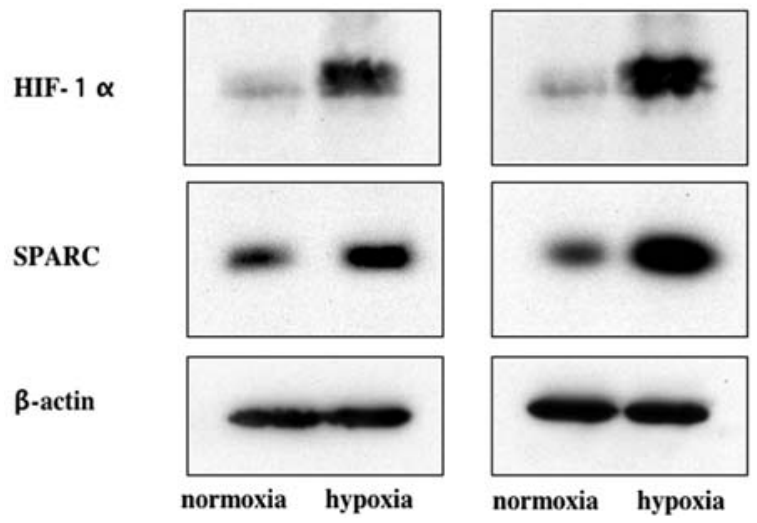

Figure 7. The expression of HIF-1 $\alpha$ and SPARC proteins under hypoxic conditions was examined by Western blot analysis. $\beta$-actin was used as an internal control. After $48 \mathrm{~h}$ of hypoxic treatment, HIF- $1 \alpha$ and SPARC proteins were markedly overexpressed compared with those under normoxic conditions.

adhesions, enzymatic degradation of extracellular matrix, and cell migration (25). These processes are related, and the biological functions of the components that participate in these processes depend on a particular tissue environment and are particularly affected by the ECM of the target organ. The ECM components of the brain are quite different from those of other organs $(26,27)$. Therefore, we established organotypic brain slice cultures that are analogous to normal brain conditions in vivo (19).

Using this model, we investigated the migration and invasion of glioma cells under actual conditions of the normal brain. In the co-culture of a glioma spheroid and a rat brain slice, it was demonstrated that the invasion of glioma cells was inhibited by downregulation of SPARC expression. In addition, intracerebral injection of glioma cells transfected with SPARC siRNA in nude mice resulted in the formation of a non-invasive tumor. Invasion of glioma cells transfected with SPARC siRNA was markedly reduced compared with control siRNA-transfected cells in the tumor-transfected model. These results indicate that SPARC can play an important role in the invasion of glioma cells both in vitro and in vivo.

In the previous reports, secretion levels of SPARC were considered to have a substantial effect on tumor invasion. The low or intermediate levels of SPARC obtained by transfection of SPARC induced low or high adhesiveness, respectively. However, very high levels of SPARC acted to promote its de-adhesive function (8). These may explain the paradoxical situation that both low and high levels of SPARC can promote more aggressive invasion than intermediate levels (8). Although the molecular mechanism of SPARC on glioma invasion remains unclear, SPARC has been reported to activate membrane type 1-matrix metalloproteinase (MMP) and MMP-2 (29). SPARC siRNA reduced the activation of phosphorylation of AKT, focal adhesion kinase, and integrinlinked kinase $(28,30)$. However, we could not demonstrate the inhibitory effect of SPARC siRNA on MMP gene expression (data not shown). Further studies are required for elucidating the intracellular signaling events of SPARC in glioma invasion.

In this study, we also investigated the expression of SPARC under hypoxic stress, which is considered to play an important role in tumor invasion and thought to be a critical factor in the poor prognosis of malignant gliomas. Under hypoxic conditions, the expression of SPARC and HIF- $1 \alpha$ proteins was highly upregulated in glioma cells. We have previously demonstrated that HIF- $1 \alpha$ is an important regulatory factor for the mobility of glioma cells under hypoxic conditions (11). HIF-1 $\alpha$ protein is regulated by oxygen, accumulates under low oxygen stimulation, and

\section{U251MG}

HIF- $1 \alpha$
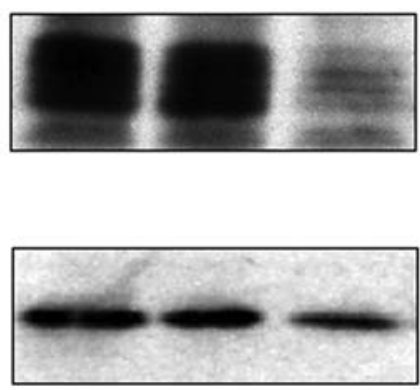

SPARC

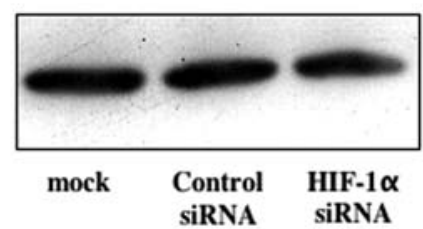

\section{U373MG}
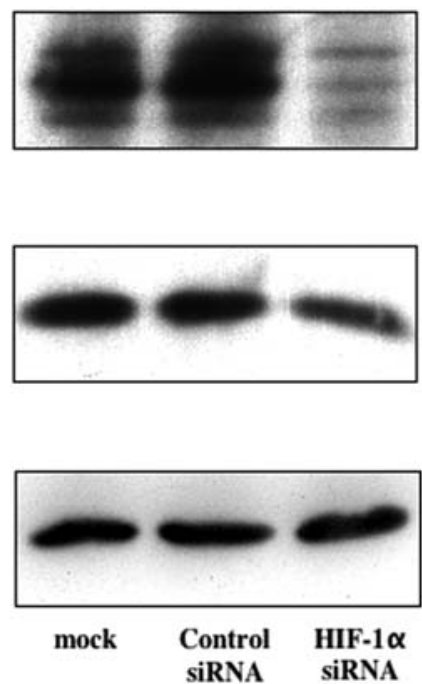

Figure 8. Effects of HIF-1 $\alpha$ siRNA on SPARC protein expression were examined by Western blot analysis. HIF-1 $\alpha$ and SPARC protein expression after $48 \mathrm{~h}$ of hypoxic treatment in non-treated cells (mock), cells treated with control siRNA, and those treated with HIF-1 $\alpha$ siRNA are shown. Transfection with HIF- $1 \alpha$ siRNA suppressed HIF-1 $\alpha$ and SPARC protein synthesis in U251MG and U373MG cells. 
affects various aspects of tumor biology including cell proliferation, cell survival, angiogenesis, and ECM metabolism. In immunohistochemical studies, HIF-1 $\alpha$ is observed specifically in the periphery of the necrotic regions of malignant gliomas (31). When we suppressed HIF-1 $\alpha$ by siRNA under hypoxic conditions, SPARC was also downregulated in conjunction with HIF-1 $\alpha$. These findings suggest the possibility of some signaling between HIF- $1 \alpha$ and SPARC under low oxygen conditions. These results lead to a hypothesis that overexpression of HIF-1 $\alpha$ induced by hypoxic stress stimulates SPARC expression, promotes invasion of hypoxic cells into the normoxic adjacent brain, and delays cell growth. After the dissolution of hypoxic stress, reduction of SPARC expression may suppress glioma cell invasion and recover glioma cell proliferation. These findings support the hypothesis that glioma cells can either 'go' or 'grow' but not both (32). Elucidation of this unique intracellular signal transduction under a hypoxic environment may offer a new therapeutic approach for glioma cell invasion.

In conclusion, we demonstrated that the suppression of SPARC expression inhibited the motile and invasive activity of human malignant glioma cells. SPARC was upregulated by hypoxia, and treatment with HIF-1 $\alpha$ siRNA suppressed SPARC expression. SPARC protein appears to be a critical factor in glioma cell invasion particularly when the cells are exposed to hypoxic conditions, which are produced by human malignant gliomas. Although additional studies will be necessary to elucidate the mechanism of the effect of SPARC on glioma cell motility, targeting the SPARC molecule may present a promising therapeutic strategy against malignant glioma invasion.

\section{References}

1. Motamed K: SPARC (osteonectin/BM-40). Int J Biochem Cell Biol 31: 1363-1366, 1999.

2. Sage EH and Bornstein P: Extracellular proteins that modulate cell-matrix interactions. SPARC, tenascin and thrombospondin. J Biol Chem 266: 14831-14834, 1991.

3. Sage H, Vernon RB, Decker J, Funk S and Iruela-Arispe ML: Distribution of the calcium-binding protein SPARC in tissues of embryonic and adult mice. J Histochem Cytochem 37: 819-829, 1989.

4. Sage H, Vernon RB, Funk SE, Everitt EA and Angello J: SPARC, a secreted protein associated with cellular proliferation, inhibits cell spreading in vitro and exhibits $\mathrm{Ca}^{2+}$-dependent binding to the extracellular matrix. J Cell Biol 109: 341-356, 1989.

5. Greenwood JA and Murphy-Ullrich JE: Signaling of deadhesion in cellular regulation and motility. Microsc Res Tech 43: 420-432, 1998.

6. Rempel SA, Golembieski WA, Ge S, Lemke N, Elisevich K, Mikkelsen T and Gutiérrez JA: SPARC: a signal of astrocytic neoplastic transformation and reactive response in human primary and xenograft gliomas. J Neuropathol Exp Neurol 57: 1112-1121, 1998.

7. Rempel SA, Golembieski WA, Fisher JL, Maile M and Nakeff A: SPARC modulates cell growth, attachment and migration of U87 glioma cells on brain extracellular matrix proteins. J Neurooncol 53: 149-160, 2001.

8. Schultz C, Lemke N, Ge S, Golembieski WA and Rempel SA: Secreted protein acidic and rich in cysteine promotes glioma invasion and delays tumor growth in vivo. Cancer Res 62: 6270-6277, 2002.

9. Alvarez MJ, Prada F, Salvatierra E, et al: Secreted protein acidic and rich in cysteine produced by human melanoma cells modulates polymorphonuclear leukocyte recruitment and anti-tumor cytotoxic capacity. Cancer Res 65: 5123-5132, 2005 .
10. Rich JN, Hans C, Jones B, et al: Gene expression profiling and genetic markers in glioblastoma survival. Cancer Res 65: 4051-4058, 2005.

11. Fujiwara S, Nakagawa $\mathrm{K}$, Harada $\mathrm{H}$, et al: Silencing hypoxiainducible factor-1alpha inhibits cell migration and invasion under hypoxic environment in malignant gliomas. Int J Oncol 30: 793-802, 2007

12. Mosmann T: Rapid colorimetric assay for cellular growth and survival: application to proliferation and cytotoxicity assays. J Immunol Methods 65: 55-63, 1983

13. Ohnishi T, Arita $\mathrm{N}$ and Hayakawa T: Motility factor produced by malignant glioma cells: role in tumor invasion. J Neurosurg 73: 881-888, 1990.

14. Ohnishi T, Arita N and Hiraga S: Fibronectin-mediated cell migration promotes glioma cell invasion through chemokinetic activity. Clin Exp Metastasis 15: 538-546, 1997.

15. Albini A, Iwamoto Y, Kleinman HK, Martin GR, Aaronson SA and Kozlowski JM: A rapid in vitro assay for quantitating the invasive potential of tumor cells. Cancer Res 47: 3239-3245, 1987.

16. Amer AP, De Armond SJ, Spencer DR, Coopersmith PF, Ramos DM and Rosenblum ML: Development of an in vitro extracellular matrix assay for studies of brain tumor cell invasion. J Neurooncol 20: 1-15, 1994.

17. Ohnishi T, Arita N, Hayakawa T, Kawahara K, Kato K and Kakinuma A: Purification of motility factor (GMF) from human malignant glioma cells and its biological significance in tumor invasion. Biochem Biophys Res Commun 193: 518-525, 1993.

18. Schor SL, Schor AM and Winn B: The use of three-dimensional collagen gels for the study of tumor cell invasion in vitro: experimental parameters influencing cell migration into the gel matrix. Int J Cancer 29: 57-62, 1982.

19. Ohnishi T, Matsumura H, Izumoto S, Hiraga S and Hayakawa T: A novel model of glioma cell invasion using organotypic brain slice culture. Cancer Res 58: 2935-2940, 1998

20. Stoppini L, Buchs PA and Muller D: A simple method for organotypic cultures of nervous tissue. J Neurosci Methods 37: 173-182, 1991 .

21. Murakami M, Goto S, Yoshikawa M, et al: The invasive features of glial and non-central nervous system tumor cells are different on organotypic brain slices from newborn rats. Int J Oncol 18: 721-727, 2001.

22. Nagato $\mathrm{S}$, Nakagawa $\mathrm{K}$, Harada $\mathrm{H}$, et al: Downregulation of laminin alpha4 chain expression inhibits glioma invasion in vitro and in vivo. Int J Cancer 117: 41-50, 2005.

23. Motamed K and Sage EH: Regulation of vascular morphogenesis by the matricellular protein SPARC. Kidney Int 51: 1383-1387, 1997.

24. Gooden MD, Vernon RB, Bassuk JA and Sage EH: Cell cycle-dependent nuclear location of the matricellular protein SPARC: association with the nuclear matrix. J Cell Biochem 74: 152-167, 1999 .

25. Liotta LA, Rao CN and Wewer UM: Biochemical interactions of tumor cells with the basement membrane. Ann Rev Biochem 55: 1037-1057, 1986.

26. Paetau A, Mellstom K, Vaheri A and Haltia M: Distribution of a major connective tissue protein, fibronectin, in normal and neoplastic human nervous tissue. Acta Neuropathol 51: 47-51, 1980.

27. Rutka JT, Apodaca G, Stern R and Rosenblum M: The extracellular matrix of the central and peripheral nervous systems: structures and function. J Neurosurg 69: 155-170, 1988.

28. Shi Q, Bao S, Song L, Wu Q, Bigner DD, Hjelmeland AB and Rich JN: Targeting SPARC expression decreases glioma cellular survival and invasion associated with reduced activities of FAK and ILK kinases. Oncogene 26: 4084-4094, 2007.

29. McClung HM, Thomas SL, Osenkowski P, et al: SPARC upregulates MT1-MMP expression, MMP-2 activation, and the secretion and cleavage of galectin-3 in U87MG glioma cells. Neurosci Lett 419: 172-177, 2007.

30. Shi Q, Bao S, Maxwell JA, et al: Secreted protein acidic, rich in cysteine (SPARC), mediates cellular survival of gliomas through AKT activation. J Biol Chem 279: 52200-52209, 2004.

31. Zagzag D, Zhong H, Scalzitti JM, Laughner E, Simons JW and Semenza GL: Expression of hypoxia-inducible factor 1alpha in brain tumors: association with angiogenesis, invasion and progression. Cancer 88: 2606-2618, 2000.

32. Giese A, Loo MA, Tran N, Haskett D, Coons SW and Berens ME: Dichotomy of astrocytoma migration and proliferation. Int $\mathrm{J}$ Cancer 67: 275-282, 1996. 